\title{
Ability to Reverse Deeper Levels of Unintended Sedation
}

\author{
John Morse $^{a}$ Giorgos Bamias ${ }^{b}$ \\ ${ }^{a}$ Cowichan District Hospital, Duncan, B.C., Canada; ${ }^{b}$ 1st Department of Internal Medicine - Propaedeutic, \\ Laiko General Hospital of Athens, Athens, Greece
}

\section{Key Words}

Reversal agents $\cdot$ Naloxone $\cdot$ Flumazenil

\begin{abstract}
During gastrointestinal endoscopy, patients may reach a level of sedation that is deeper (i.e. deep sedation) than intended to be (i.e. moderate sedation). In such cases the ability to restore respiratory and cardiovascular function is critical. Supportive measures should be combined with administration of specific pharmacologic antagonists in cases of imminent ventilatory failure. Naloxone rapidly reverses sedation and respiratory depression due to previously administered narcotics, whereas flumazenil overturns the effects of midazolam on the central nervous system. Both agents are administered intravenously in repeated doses according to the patient's response. Caution, however, is required, as the halflives of these reversal agents are shorter than those of the respective agonists and re-sedation may occur. Acute withdrawal syndromes may take place in chronic users of opiates or benzodiazepine. Product monographs along with administration protocols may be demonstrated as a wall chart, to ascertain their safe and effective use in endoscopy units.
\end{abstract}

Copyright $\odot 2010$ S. Karger AG, Basel

\section{Introduction}

Sedation and analgesia are commonly used in gastrointestinal endoscopy because they minimize patient anxiety, decrease discomfort during the procedure, and create amnesia of the examination. These goals are usually achieved through moderate (or 'conscious') sedation, which is the level of sedation used in most endoscopic procedures of the gastrointestinal tract [1]. It is, however, understood that sedation occurs in a continuous scale from anxiolysis to general anesthesia, as defined by various levels of patient alertness, as well as respiratory and cardiovascular function [2]. As a result of this continuum, it is not unusual for patients undergoing endoscopy to reach a level of sedation that is deeper than intended by the agents and dosages administered [3, 4]. This, in turn, increases the potential for serious complications, including apnea. In the case of such an occurrence, the ability to reverse deeper levels of sedation should be readily available.

\begin{tabular}{|c|c|}
\hline KARGER & $\begin{array}{l}\text { (c) } 2010 \text { S. Karger AG, Basel } \\
0012-2823 / 10 / 0822-0094 \$ 26.00 / 0\end{array}$ \\
\hline $\begin{array}{l}\text { Fax +41 } 613061234 \\
\text { E-Mail karger@karger.ch } \\
\text { www.karger.com }\end{array}$ & $\begin{array}{l}\text { Accessible online at: } \\
\text { www.karger.com/dig }\end{array}$ \\
\hline
\end{tabular}




\section{Reversal Agents}

Two classes of sedatives/analgesics have specific antagonists [5]. In particular, the effects of opioids (meperidine and fentanyl) can be reversed with naloxone, whereas flumazenil is a specific antagonist for benzodiazepines and is used to block the action of midazolam.

\section{Naloxone Hydrochloride}

Naloxone hydrochloride is administered intravenously and will rapidly reverse sedation as well as respiratory depression due to previously administered narcotics [6]. In an oversedated patient, 0.4 - to 2.0 -mg boluses are given every 2-3 min. If necessary an intravenous infusion can be used [7]. Smaller doses may be appropriate in elders since naloxone induces secretion of catecholamines and may create cardiovascular instability [8]. The duration of treatment depends on the half-life of the narcotic being reversed, as fentanyl has a much shorter T1/2 than meperidine. In fact, naloxone is cleared faster than meperidine. Therefore, the possibility of re-sedation after cessation of naloxone activity should be taken into consideration when large amounts of meperidine have been administered. This should be of particular concern when patient discharge is considered. Caution is also required in chronic opioid abusers, as administration of naloxone can precipitate acute withdrawal syndrome. The latter may include pain, hypertension, tachycardia, and pulmonary edema.

\section{Flumazenil}

Flumazenil selectively binds to the $\mathrm{GABA}_{\mathrm{A}}$ receptor complex, prevents the attachment of benzodiazepines to their receptor, and inhibits or reverses their effects on the central nervous system [9]. As a result, flumazenil blocks midazolam- (alone or with opiates) induced sedation and respiratory depression $[10,11]$. In the oversedated individual, flumazenil is administered through intravenous boluses of $0.2-0.5 \mathrm{mg}$. A common practice is to administer $0.2 \mathrm{mg}$ over $30 \mathrm{~s}$, and increase to $0.3 \mathrm{mg}$ in the absence of response. Additional repeated doses of $0.5 \mathrm{mg}$ can be given, up to a maximum total of $3 \mathrm{mg}$. Flumazenil has a rapid onset of action (1-3 $\mathrm{min}$ ), reaches $80 \%$ of the response within $3 \mathrm{~min}$ and demonstrates its peak effect in 6-10 min. After intravenous administration, the half-life of flumazenil is between 40 and $80 \mathrm{~min}$. Since the duration of the sedative effect of midazolam may reach 80 min, there is always a possibility for re-sedation of the patient, despite an initial response to flumazenil. Similarly to naloxone, flumazenil can cause acute withdrawal syndrome, including seizures, in patients who receive benzodiazepines chronically [12]. As there is no adequate data for usage of flumazenil in pregnancy, it should be used only when there is an absolute indication [13].

\section{Clinical Practice}

Reversal agents cannot be relied upon for long-term reversal of sedation, e.g. just prior to discharge, because both naloxone and flumazenil have short half-lives, which can be shorter than the duration on the central nervous system effects of opiates and benzodiazepines, respectively. As a consequence, routine usage of these agents for the reversal of opiate- or benzodiazepine-induced sedation is discouraged by recent guidelines [2]. This, in fact, is reflected in the low utilization of reversal agents in clinical practice. Wehrmann et al. [14] reported that only 4 of 98 patients who received midazolam during gastrointestinal procedures required flumazenil administration. Similarly, in a nationwide US survey, Cohen et al. [15] reported that although sedatives were used in $98.2 \%$ of upper gastrointestinal endoscopies and $98.8 \%$ of colonoscopies, the frequency of antagonist usage was as low as $0.8 \%$.

Although the routine usage of reversal agents is not recommended, these drugs should be available for use in emergencies, in particular when respiratory depression becomes life-threatening, the patient becomes apneic or hypoxemic, and when intubation and bagging is being considered. In such cases, naloxone or flumazenil administration should always be combined with additional supportive measures: (1) the patients should be encouraged to take deep breaths and supplemental oxygen must be delivered; (2) fluid resuscitation may be necessary in opiate overdosage; (3) if spontaneous ventilation is not sufficient to maintain oxygenation, positive pressure ventilation should not be delayed; and (4) frequent assessment of the patient's condition is mandatory for continuously evaluating the resuscitating efforts [2]. In addition, special care should be taken in patients in whom problems in maintaining airway control or delivering positive pressure ventilation are expected.

In endoscopy units that administer opiate- and midazolam-based sedation/analgesia, the specific antagonists naloxone and flumazenil should be readily available, as this may be associated with decreased frequency for adverse outcomes. In addition, instructions on how to use them should be accessible and easy to reach. This is particularly relevant for busy endoscopy suites, where 
personnel may not be familiar with the use of reversal agents, as they rarely use them. In such cases the product monographs may be demonstrated as a wall chart, along with posted administration protocols. These simple measures will facilitate the safe and effective use of reversal agents. Equally important is the need for extended observation of patients after administration of naloxone or flumazenil, as recurrence of central nervous system depression may be observed when the antagonistic effects have ceased.
In conclusion, the use of sedation protocols that incorporate routine use of opioid/benzodiazepine antagonists should be avoided as they may generate a false estimation of the patient's condition. On the other hand, personnel involved in sedative administration should be familiar with the specifics of each reversal agent and be able to administer it in a timely and safe manner.

\section{References}

1 Rex DK: Review article: moderate sedation for endoscopy: sedation regimens for nonanaesthesiologists. Aliment Pharmacol Ther 2006;24:163-171.

$>2$ American Society of Anesthesiologists Task Force on Sedation and Analgesia by NonAnesthesiologists: Practice guidelines for sedation and analgesia by non-anesthesiologists. Anesthesiology 2002;96:1004-1017.

$>3$ Patel S, Vargo JJ, Khandwala F, Lopez R, Trolli P, Dumot JA, Conwell DL, Zuccaro G: Deep sedation occurs frequently during elective endoscopy with meperidine and midazolam. Am J Gastroenterol 2005;100: 2689-2695.

4 King KP: Where is the line between deep sedation and general anesthesia? Am J Gastroenterol 2002;97:2485-2486.

$\checkmark 5$ Cohen LB, Delegge MH, Aisenberg J, Brill JV, Inadomi JM, Kochman ML, Piorkowski JD: AGA institute review of endoscopic sedation. Gastroenterology 2007;133:675701
Dahan A, Aarts L, Smith TW: Incidence, reversal, and prevention of opioid-induced respiratory depression. Anesthesiology 2010; 112:226-238.

77 Greenwald B: Narcan use in the endoscopy lab: an important component of patient safety. Gastroenterol Nurs 2004;27:20-21.

$\checkmark 8$ American Society For Gastrointestinal Endoscopy: Guidelines for conscious sedation and monitoring during gastrointestinal endoscopy. Gastrointest Endosc 2003;58:317322.

$\checkmark 9$ Mora CT, Torjman M, White PF: Sedative and ventilator effects of midazolam infusion: effect of flumazenil reversal. Can J Anaesth 1995;42:677-684.

10 Kankaria A, Lewis JH, Ginsberg G, Gallagher J, al-Kawas FH, Nguyen CC, Fleischer DE, Benjamin SB: Flumazenil reversal of psychomotor impairment due to midazolam or diazepam for conscious sedation for upper endoscopy. Gastrointest Endosc 1996;44: $416-421$.
11 Gross JB, Bloouin RT, Zanberg S, Conard P, Jurgen $\mathrm{H}$ : Effect of flumazenil on ventilatory drive during sedation with midazolam and alfentanil. Anesthesiology 1996;85:713-720.

-12 Mintzer MZ, Stoller KB, Griffiths RR: A controlled study of flumazenil-precipitated withdrawal in chronic low-dose benzodiazepine users. Psychopharmacology (Berl) 1999; 147:200-209.

13 Cappell MS: Sedation and analgesia for gastrointestinal endoscopy during pregnancy. Gastrointest Endosc Clin N Am 2006;16:131.

14 Wehrmann T, Kokabpick S, Lembcke B, Caspary WF, Seifert H: Efficacy and safety of intravenous propofol sedation during routine ERCP: a prospective, controlled study. Gastrointest Endosc 1999;49:677-683.

15 Cohen LB, Wecsler JS, Gaetano JN, Benson BA, Miller KM, Durkalski V, Aisenberg J: Endoscopic sedation in the United States: results from a nationwide survey. Am J Gastroenterol 2006;101:967-974. 